Article

\title{
Incorporation of Rubber Powder as Filler in a New Dry-Hybrid Technology: Rheological and 3D DEM Mastic Performances Evaluation
}

\author{
Valeria Vignali *, Francesco Mazzotta, Cesare Sangiorgi, Andrea Simone, Claudio Lantieri and \\ Giulio Dondi \\ DICAM Department, University of Bologna, Viale Risorgimento 2, Bologna 40136, Italy; \\ francesco.mazzotta2@unibo.it (F.M.); cesare.sangiorgi4@unibo.it (C.S.); andrea.simone@unibo.it (A.S.); \\ claudio.lantieri2@unibo.it (C.L.); giulio.dondi@unibo.it (G.D.) \\ * Correspondence: valeria.vignali@unibo.it; Tel.: +39-051-209-3522 \\ Academic Editor: Geminiano Mancusi \\ Received: 25 July 2016; Accepted: 12 October 2016; Published: 18 October 2016
}

\begin{abstract}
In recent years, the use of crumb rubber as modifier or additive within asphalt concretes has allowed obtaining mixtures able to bind high performances to recovery and reuse of discarded tires. To date, the common technologies that permit the reuse of rubber powder are the wet and dry ones. In this paper, a dry-hybrid technology for the production of Stone Mastic Asphalt mixtures is proposed. It allows the use of the rubber powder as filler, replacing part of the limestone one. Fillers are added and mixed with a high workability bitumen, modified with SBS (styrene-butadiene-styrene) polymer and paraffinic wax. The role of rubber powder and limestone filler within the bituminous mastic has been investigated through two different approaches. The first one is a rheological approach, which comprises a macro-scale laboratory analysis and a micro-scale DEM simulation. The second, instead, is a performance approach at high temperatures, which includes Multiple Stress Creep Recovery tests. The obtained results show that the rubber works as filler and it improves rheological characteristics of the polymer modified bitumen. In particular, it increases stiffness and elasticity at high temperatures and it reduces complex modulus at low temperatures.
\end{abstract}

Keywords: rubber powder; limestone filler; mastics; Multiple Stress Creep Recovery; Frequency Sweep test; 3D discrete element modeling; burger viscoelastic model; Dynamic Shear Rheometer; complex modulus; phase angle

\section{Introduction}

In order to minimize the environmental impacts of roads construction and maintenance, it is necessary to find solutions able to increase the pavements performance while reducing the externalities. In this context, the use of recycled materials, suitable for other re-use, must be developed and promoted [1-5].

The fields of application of crumb rubber in road constructions are various. The research studies that validate them are as numerous as the amount of positive results achieved in recycling this material. The use of recycled rubber from End of Life Tires (ELT) into asphalt concretes started back in the 1960s. The technology that has spread more is the so-called Asphalt Rubber (AR) one. AR binders are produced with the industrial process invented by Charles McDonald and that is at the basis of the wet process. This process starts with the mixing of ELT ground rubber with the bituminous binder, using mechanical stirring systems, working at temperatures ranging between 190 and $218{ }^{\circ} \mathrm{C}$, for a time interval of 45 to $60 \mathrm{~min}$ [6].

Numerous studies have shown that the addition of crumb rubber to the virgin bitumen, by means of the AR technology, produces binders with enhanced rheological performances. It improves, in fact, 
resistance to rutting, fatigue cracking and thermal cracking. It allows, moreover, a reduction of the thickness of asphalt overlays and reflective cracking potential $[7,8]$.

However, AR technology generates some disadvantages such as high production temperatures and long mixing reaction, with consequent energy consumption.

In order to reduce these deficiencies, a new wet process concept has been developed in the last few years. Oliveira et al. (2013) have shown that the combination of AR technology with Warm Mix Additives (WMA) improves the production conditions of asphalt mixtures. It reduces, in particular, the temperature at which the mixtures are produced and compacted, improving the personnel working conditions, with the incorporation of very limited amounts of additive [9-12].

Next to the wet technology, powdered rubber is used in asphalt mixtures with the dry technology. In this case, the rubber powder replaces a part of stone aggregates, modifying the resulting lytic skeleton and giving place to a limited interaction with the bituminous binder. The reaction between bitumen and crumb rubber can be considered negligible, because the mixtures are produced without any significant interaction time between bitumen and rubber [13]. Several studies indicate that with the dry technology is possible to produce "gap-graded" and "open-graded" mixtures. For their formulation, the same grading curve used for mixtures produced with the wet method may be introduced. Bitumen proportion must be determined taking into account that the rubber tends to absorb bitumen oils during the mixing, transport and placement [14].

In this paper, a dry-hybrid technology for the production of Stone Mastic Asphalt mixtures is proposed. It is called "Dry-Hybrid Technology" and it allows the use of the rubber powder as filler, replacing part of the limestone one. Fillers are mixed with a high workability bitumen, modified with SBS (styrene-butadiene-styrene) polymer and paraffinic wax.

The idea is to manually add into the mixer the rubber powder, without significant alterations of the production process of traditional modified asphalt mixtures. In this way, the rubber can be considered as a filler and not an aggregate.

The aim of this technology is to improve both mixture mechanical and workability characteristics. The mix of elastic properties performed by crumb rubber powder and of the advantages given by modified bitumen and additives, in fact, can produce mix oxidation reduction and performance increasing at high temperatures [9].

In this way, moreover, it is possible to reduce costs and externalities produced by bituminous binders traditionally modified with recycled rubber. The mixing of bitumen and rubber at reduced temperatures permits to decrease environmental emissions and energetic costs. Recent research studies, moreover, have been demonstrated that trough this technique the workers are less susceptible to harmful substances produced during the mix compaction $[15,16]$.

The proposed technology has been applied on Stone Mastic Asphalts (SMA) because they have a high stone content, which forms a gap-graded skeleton-like stone structure, filled with a high viscosity bituminous mastic of bitumen and filler. SMA, properly designed and produced, has excellent properties. The stone skeleton, with its high internal friction, gives excellent shear resistance. The mastic, voidless and binder rich, gives to the mix good durability, resistance to cracking and good stability at high temperatures. The surface texture is rougher than that of dense graded asphalt and it assures good skid resistance, proper light reflection, reduced water spray and lower traffic noise [17-20].

In this research study, two different approaches have been used:

- Rheological approach, which comprises a macro-scale laboratory analysis and a micro-scale simulation. In the first, Frequency Sweep tests (FS) have been implemented. In the second, a micromechanical modeling, able to predict the rheological behavior of mastics starting from the understanding of their internal interaction, has been used. Since Discrete particle Element Method (DEM) treats particles as distinct bodies that interact together at contact points, it can be a very useful tool [21-25]. The software Particle Flow Code (PFC) was used in this study [26]. 
The DEM simulation, in particular, has been used in order to evaluate the rubber effects and the interaction among limestone filler, rubber and bituminous matrix inside the mastics.

- Performance approach, which comprises Multiple Stress Creep Recovery (MSCR) tests, in order to evaluate the permanent deformation resistance of the mastics also in nonlinear analysis.

The obtained data permit validating the proposed "Dry-Hybrid Technology".

\section{Materials}

\subsection{Mastics Design}

To evaluate the proposed "Dry-Hybrid Technology" for the production of Stone Mastic Asphalts, three different SMAs have been investigated (SMA, SMA1.2 and SMA0.7).

The first one (SMA) has been designed using standard proportion, according to the Italian technical specifications [27]. The other two, instead, have been designed in order to study the influence of rubber on the mix performance. In SMA1.2, in particular, the bitumen content has been increased, to improve the rubber percentage respect to the limestone filler one. In SMA0.7, instead, the bitumen content has been reduced, to evaluate the inferior limit of rubber amount in the mixture.

The percentages of bitumen, limestone filler and rubber on the weight of aggregate of the three SMAs are reported in Table 1.

Table 1. SMA components (\%).

\begin{tabular}{cccc}
\hline SMA & Bitumen & Limestone Filler & Crumb Rubber \\
\hline SMA & 6.60 & 9.00 & 0.00 \\
SMA1.2 & 8.50 & 5.00 & 1.20 \\
SMA0.7 & 7.50 & 5.00 & 0.75 \\
\hline
\end{tabular}

Starting from the designed SMAs, according to their proportions, three corresponding mastics have been extracted (MasSMA, MasSMA1.2 and MasSMA0.7).

They were produced with a warm mixing process. Warm bitumen, modified with polymer and waxes, and two types of filler (limestone filler and crumb rubber) have been used. The bitumen, in particular, was prepared by adding paraffinic wax ( $2 \%$ in weight of bitumen) and SBS ( $5 \%$ in weight of bitumen) to a neat 70/100 pen binder. The wax, instead, was obtained from coal gasification using the Fisher-Tropsch process [9]. The wax, which has a melting point of $90^{\circ} \mathrm{C}$, was added at $130{ }^{\circ} \mathrm{C}$. In order to avoid phase separation, the samples were mixed with a Silverson mixer L4R (Silverson Machines Ltd., Chesham, UK), for one minute. The characteristics of the base bitumen, provided from the producer, are shown in Table 2.

Table 2. Properties of the warm modified bitumen (provided from the producer).

\begin{tabular}{cccc}
\hline Property & Unit & Characteristic Value & Standard \\
\hline Penetration @25 ${ }^{\circ} \mathrm{C}$ & $\mathrm{dmm}$ & $25 \div 55$ & EN 1426 [28] \\
Softening Point & ${ }^{\circ} \mathrm{C}$ & 70 & EN 1427 [29] \\
Force Ductility test $@ 10{ }^{\circ} \mathrm{C}$ & $\mathrm{J} / \mathrm{cm}^{3}$ & 3 & EN 13589 [30] \\
Dynamic Viscosity @ $160^{\circ} \mathrm{C}$ & $\mathrm{Pa} \cdot \mathrm{s}$ & $0.4 \div 0.7$ & EN 12596 [31] \\
Elastic Recovery @ $25{ }^{\circ} \mathrm{C}$ & $\%$ & 80 & EN 13398 [32] \\
\hline
\end{tabular}

In order to be used as fillers, both limestone filler and crumb rubber have been characterized geometrically and volumetrically, respectively through a gradation analysis and their volumetric mass. Rigden Voids and Delta Ring and Ball were also performed according to EN standards. Table 3 shows the components characteristics. 
Table 3. Percentages of bitumen, limestone filler and rubber on weight of bitumen.

\begin{tabular}{ccccc}
\hline Property & Unit & Limestone Filler & Crumb Rubber & Standard \\
\hline Particle size range & $\mathrm{mm}$ & $0 \div 0.063$ & $0 \div 0.4$ & EN 933-10 [33] \\
Particle density & $\mathrm{Mg} / \mathrm{m}^{3}$ & 2.73 & 1.01 & EN 1097-7 [34] \\
Rigden voids & $\%$ & 33.82 & - & EN 1097-4 [35] \\
$\Delta$ Ring and Ball & ${ }^{\circ} \mathrm{C}$ & 8 & 12 & EN 13179-1 [36] \\
\hline
\end{tabular}

The determination of limestone filler $\left(C_{f}\right)$ and rubber $\left(C_{r}\right)$ concentration in the mastic, based on mass, is given by:

$$
\begin{gathered}
C_{f}=\frac{M_{f}}{M_{b}+M_{f}+M_{r}} \cdot 100 \\
C_{r}=\frac{M_{r}}{M_{b}+M_{f}+M_{r}} \cdot 100
\end{gathered}
$$

where $M_{f}$ is the mass of limestone filler in the mastic, $M_{r}$ is the mass of rubber in the mastic and $M_{b}$ is the mass of bitumen in the mastic.

The determination of ratio of limestone filler $\left(R_{f}\right)$ and of rubber $\left(R_{r}\right)$ to bitumen, based on mass, is given by:

$$
\begin{aligned}
R_{f} & =\frac{M_{f}}{M_{b}} \\
R_{r} & =\frac{M_{r}}{M_{b}}
\end{aligned}
$$

For each mastic, the comparison of limestone filler to bitumen (by mass) and rubber to bitumen (by mass) ratios is shown in Table 4 . The requirement within Superpave system is a filler to bitumen ratios ranging between 0.6 and 1.2 , based on mass.

Table 4. Mastics composition.

\begin{tabular}{ccccc}
\hline Mastic & $C_{\boldsymbol{f}} \mathbf{( \% )}$ & $\boldsymbol{C}_{\boldsymbol{r}} \mathbf{( \% )}$ & $\boldsymbol{R}_{\boldsymbol{f}}$ & $\boldsymbol{R}_{\boldsymbol{r}}$ \\
\hline MasSMA & 136 & 0 & 1.36 & 0.00 \\
Mas1.2 & 59 & 14 & 0.59 & 0.14 \\
Mas0.7 & 67 & 10 & 0.67 & 0.10 \\
\hline
\end{tabular}

In this investigation, the sum of limestone filler to bitumen $\left(R_{f}\right)$ and rubber to bitumen $\left(R_{r}\right)$ ratios is between 0.73 and 0.77 , excluding the mastic containing only limestone filler (MasSMA), for which the ratio of 1.36 exceeds the Superpave upper limit.

\subsection{Mastics Volumetric Analysis}

The volumetric analysis has been conducted on the three mastics. The calculation of the compositional volume of bitumen, filler and rubber particle $\left(V_{f}, V_{r}\right.$, and $\left.V_{b}\right)$ has been obtained through the following equations:

$$
\begin{gathered}
V_{f}=\frac{\frac{M_{f}}{S_{f}}}{\frac{M_{b}}{S_{b}}+\frac{M_{f}}{S_{f}}+\frac{M_{r}}{S_{r}}} \cdot 100 \\
V_{r}=\frac{\frac{M_{r}}{S_{r}}}{\frac{M_{b}}{S_{b}}+\frac{M_{f}}{S_{f}}+\frac{M_{r}}{S_{r}}} \cdot 100
\end{gathered}
$$




$$
V_{b}=\frac{\frac{M_{b}}{S_{b}}}{\frac{M_{b}}{S_{b}}+\frac{M_{f}}{S_{f}}+\frac{M_{r}}{S_{r}}} \cdot 100
$$

where $M_{f}$ is the mass of limestone filler in the mastic, $M_{r}$ is the mass of rubber in the mastic, $M_{b}$ is the mass of bitumen in the mastic, $S_{f}$ is the specific gravity of filler, $S_{r}$ is the specific gravity of rubber and $S_{b}$ is the specific gravity of bitumen.

The results of the equations are reported in Table 5.

Table 5. Mastics volumetric composition.

\begin{tabular}{cccc}
\hline Mastic & $\boldsymbol{V}_{\boldsymbol{f}}(\mathbf{\%})$ & $\boldsymbol{V}_{\boldsymbol{r}} \mathbf{( \% )}$ & $\boldsymbol{V}_{\boldsymbol{b}} \mathbf{( \% )}$ \\
\hline MasSMA & 33 & 0 & 67 \\
Mas1.2 & 16 & 11 & 73 \\
Mas0.7 & 19 & 7 & 74 \\
\hline
\end{tabular}

\subsection{Mastics Production}

The mastics were produced by adding the mass of limestone filler and fine crumb rubber to heated bitumen, at a temperature of $160^{\circ} \mathrm{C}$. The mix of the three components has been conducted with a traditional mixer for one minute. This procedure simulates what happens in the production phase of the industrial plant. The mixing procedures are detailed as follows:

- limestone filler was inserted into a $160{ }^{\circ} \mathrm{C}$ oven for $24 \mathrm{~h}$, to ensure moisture free particle surfaces;

- the bitumen was stored in a $5 \mathrm{~L}$ tin, preheated $7 \mathrm{~h}$ into a $160{ }^{\circ} \mathrm{C}$ oven, to make bitumen homogeneous and ready to mix;

- the accurate amount of bitumen was poured into a $1 \mathrm{~L}$ tin, and the tin with the bitumen was placed on a hot plate and kept at $160{ }^{\circ} \mathrm{C}$;

- the bitumen was mechanically stirred for $30 \mathrm{~s}$;

- the accurate mass of the limestone filler and crumb rubber was slowly added, and the mixing process followed so that fillers were homogeneously dispersed in the bitumen; and

- $\quad$ the obtained mastic was poured in a silicon mold ( $2 \mathrm{~mm}$ high and $8 \mathrm{~mm}$ diameter) and stored at $5{ }^{\circ} \mathrm{C}$ before starting the test.

\section{Mastics Rheological Behavior}

The evaluation of mastics rheological behavior has been conducted through a rheological approach. It comprises a macro-scale laboratory analysis and a micro-scale simulation.

In the first, linear viscoelastic analysis using Frequency Sweep tests (FS) have been implemented.

In the second, a DEM micromechanical modeling, able to predict the rheological behavior of mastics starting from the understanding of their internal interaction, has been used. The DEM simulation, in particular, has been performed in order to examine in depth the rubber effects and the interaction among limestone filler, rubber and bituminous matrix inside the mastics.

\subsection{Macro-Scale Laboratory Analysis}

According to EN 14770 [37], a dynamic mechanical analysis, using oscillatory tests, was performed on the three mastics. An Anton Paar MCR302 Dynamic Shear Rheometer (DSR) (Anton Paar S.r.l., Graz, Austria) was used.

Numerous research studies have shown that there is a reproducibility of the rheological tests with DSR in the study of bituminous mastics, confirming that the principles behind the rheological analysis of bitumen are validated also for these complex materials [38-41].

The tests were conducted under controlled strain, and the strain amplitude was limited within the linear viscoelastic (LVE) response of the samples (Table 6). 
Table 6. Mastics Linear Visco-Elastic range.

\begin{tabular}{ccc}
\hline Mastic & $\gamma$ LVE $(\%)$ & Temperature $\left({ }^{\circ} \mathbf{C}\right)$ \\
\hline MasSMA & 0.5 & 10 \\
Mas1.2 & 0.8 & 10 \\
Mas0.7 & 0.8 & 10 \\
\hline
\end{tabular}

Data were obtained from frequency sweep tests between 0.01 and $10 \mathrm{~Hz}$, conducted between 10 and $60^{\circ} \mathrm{C}$. The $8 \mathrm{~mm}$ measurement system with $2 \mathrm{~mm}$ gap was used in the entire temperature range. The rheological parameters obtained from frequency sweep tests were the complex shear modulus $\left(G^{*}\right)$ and phase angle $(\delta)$.

$G^{*}$ has been evaluated as a function of the absolute values of the peak to-peak shear stress ( $\left.\tau_{\text {MAX }}\right)$ and of the peak to-peak shear strain ( $\left.\gamma_{\mathrm{MAX}}\right)$, using Equation (8) [42]:

$$
|G *|=\frac{\tau_{M A X}}{\gamma_{M A X}}
$$

$\delta$ has been evaluated in terms of time lag $(\Delta t)$ between the shear stress and strain, as a function of the loading time $(t)$ using Equation (9):

$$
\delta=\frac{\Delta t}{t} \cdot 360
$$

Adopting the principle of Time-Temperature Superposition (TTS), the master curves of $G^{*}$ and $\delta$ were constructed at the reference temperature of $30^{\circ} \mathrm{C}$.

To define the horizontal shift factor value $\left(a_{t}\right)$, the Williams-Landel-Ferry (WLF) theory has been used [38-41]. In this way, $a_{t}$ is a function of two constants $\left(C_{1}\right.$ and $\left.C_{2}\right)$ and of two temperatures, the measurement one $(T)$ and the reference one $\left(T_{r e f}\right)$, according to Equation (10):

$$
\log a_{t}=\frac{C_{1} \cdot\left(T-T_{r e f}\right)}{C_{2} \cdot\left(T-T_{r e f}\right)}
$$

The master curves obtained in frequency sweep (FS) tests show differences in terms of values and trends, for both complex modulus $\left(G^{*}\right)$ and phase angle $(\delta)$ (Figure 1 ).

The combined action of rubber and limestone filler increases the characteristics given by the SBS polymer to the bitumen. It reduces the mastics thermo-sensitivity and increases the viscoelasticity range.

In terms of master curve shape, all three materials exhibit the "s-shape" with two asymptotes (one for the high temperatures and one for low temperatures), typical of asphalt mixtures.

At low frequencies (LF), from $1 \times 10^{-7} \mathrm{~Hz}$ to $1 \times 10^{-3} \mathrm{~Hz}$, Mas1.2 and Mas0.7 show complex modulus values higher than the mastic containing only limestone filler (MasSMA). At these frequencies, corresponding to high temperatures, the $14 \%$ and the $10 \%$ respectively of crumb rubber in weight on bitumen increase the complex shear modulus. Although the volumetric analysis shows that the filler presence is higher for MasSMA, the substitution of some limestone filler with fine crumb rubber increases the mastic response to permanent deformation at high temperatures.

At medium frequencies (MF), from $1 \times 10^{-3} \mathrm{~Hz}$ to $10 \mathrm{~Hz}$, the $G^{*}$ of Mas1.2 and MasSMA tend to the same values, which means that they have the same shear stress response at medium temperatures between 20 and $40^{\circ} \mathrm{C}$.

The main differences can be observed at high frequencies (HF), from $10 \mathrm{~Hz}$ to $1 \times 10^{3} \mathrm{~Hz}$, where the mastic containing limestone filler (MasSMA) tends to the glassy modulus, showing $G^{*}$ between $1 \times 10^{8}$ and $1 \times 10^{9} \mathrm{~Pa}$. At high frequencies, corresponding to low temperatures, the presence of rubber reduces the complex modulus and consequently the mastic fragile behavior. 


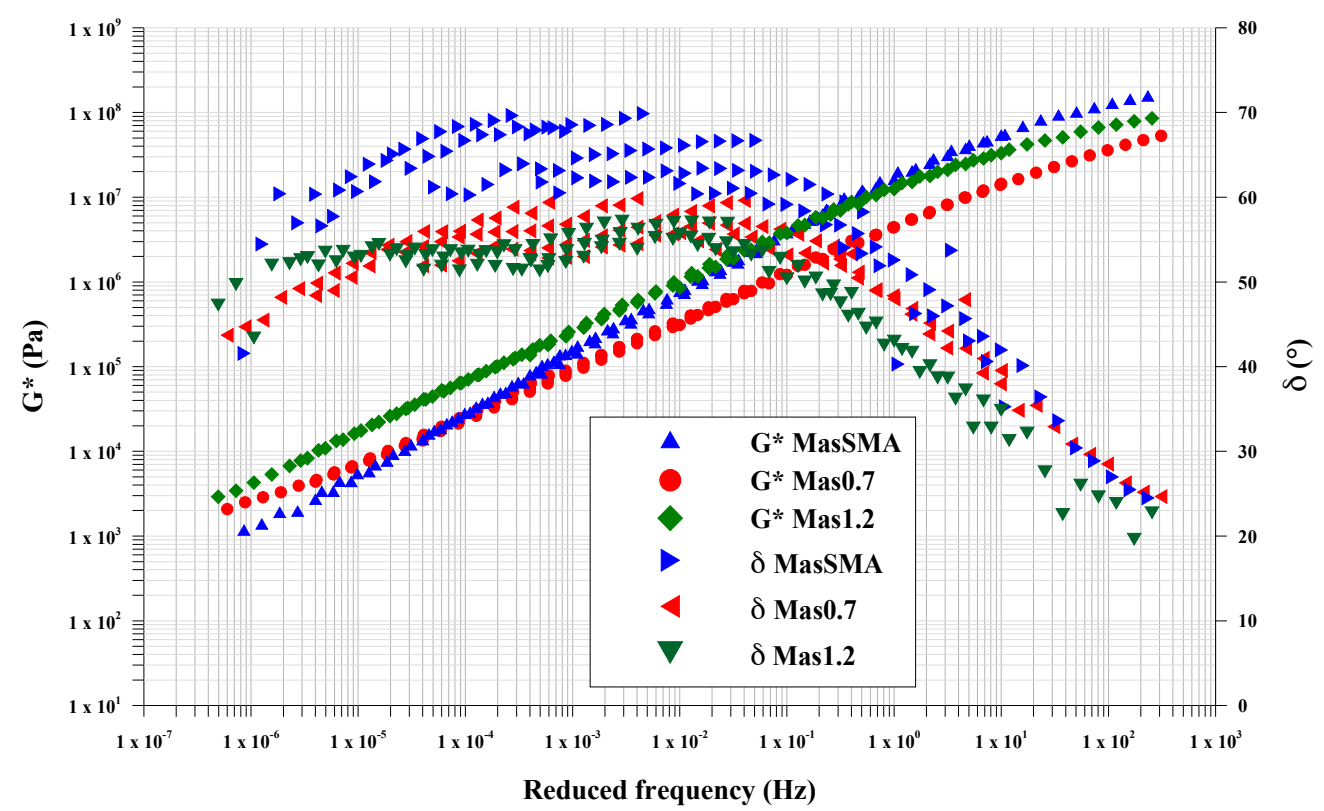

Figure 1. DSR master curves of tested mastics.

In addition, in terms of phase angle, the trend is different for the studied mastics. At high frequencies, from $10 \mathrm{~Hz}$ to $1 \times 10^{3} \mathrm{~Hz}$, Mas 0.7 and MasSMA have phase angle higher than Mas1.2, which has values between $20^{\circ}$ and $40^{\circ}$. At medium frequencies, from $1 \times 10^{-3} \mathrm{~Hz}$ to 10 , Mas 0.75 and Mas1.2 have $\delta$ values respectively between $50^{\circ}$ and $55^{\circ}$ and the MasSMA between $60^{\circ}$ and $70^{\circ}$, showing the elastic response reduction without the crumb rubber. At low frequencies, from $1 \times 10^{-7}$ to $1 \times 10^{-3} \mathrm{~Hz}$, the elastic response of the mastics containing crumb rubber is gradually exalted.

\subsection{DEM Micro-Scale Simulation}

\subsubsection{Introduction}

The laboratory analysis showed that the interaction between fine crumb rubber and limestone filler provides the mastics with higher complex modulus and lower thermo-sensitivity and phase angles. In order to deeply investigate the influence of crumb rubber as a filler on the mastic behavior, a three-dimensional discrete element modeling approach has used.

As shown by numerous research works, in fact, it is possible to understand the microscale contacts mechanisms inside the material, from which its macroscale mechanical performances derive $[21,43,44]$.

For each mastic, the discrete element simulation includes the following steps: definition of the model geometry, setting of contact material properties and simulation of the boundary and loading conditions of the frequency sweep test.

\subsubsection{Definition of the Model Geometry}

According to Vignali et al. [42] the model geometry was defined using spherical particles, contained inside walls, which simulate the DSR device.

The bitumen spheres' diameter was set to $200 \mu \mathrm{m}$, according to the magnitude of the bitumen film coating aggregates in bituminous mixes $[45,46]$.

The limestone filler spheres' diameter and the crumb rubber spheres' diameter were set to $100 \mu \mathrm{m}$, according to grading curves (Table 3), in order to reduce calculation times. In fact, it should be noted that in DEM simulation it is almost impossible to take the fine particles fully into consideration, because not only this significantly increases the computational time, but it also affects the system's capability to reach the equilibrium. 
As measured by the manufacturer, the spheres' density was set to 1040,2560 and $1200 \mathrm{~kg} / \mathrm{m}^{3}$ respectively for bitumen, limestone filler and crumb rubber. Density scaling technique was not used, despite it reducing computation time.

For each specimen, the spheres' number was calculated following the volumetric proportion showed in Table 5 .

The dynamic shear rheometer was simulated by three walls, one cylindrical and two planes. These last simulate the parallel plates that closed the cylinder at the top and at the bottom. The lower plane is fixed, while the upper one oscillates back and forth to create the shearing action. The cylinder has a contact stiffness equal to $10^{2} \mathrm{~N} / \mathrm{m}$, obtained from a calibration analysis [42].

The sample of mastic, $2 \mathrm{~mm}$ thick and $8 \mathrm{~mm}$ in diameter, was generated inside the walls (Figures 2-4).

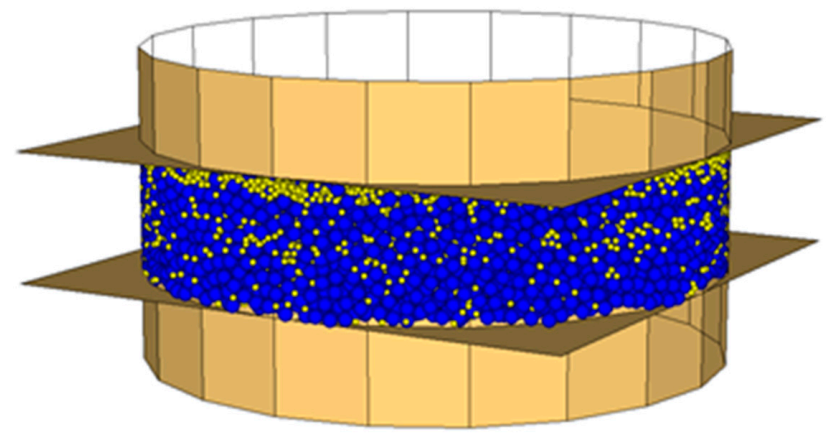

Figure 2. MasSMA, DEM simulation (bitumen particles in blue, limestone filler particles in yellow).

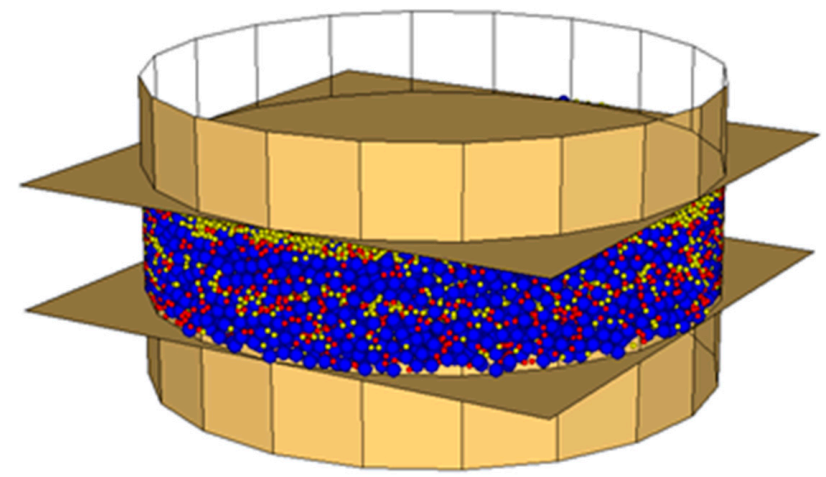

Figure 3. Mas0.7, DEM simulation (bitumen particles in blue, limestone filler particles in yellow, crumb rubber particles in red).

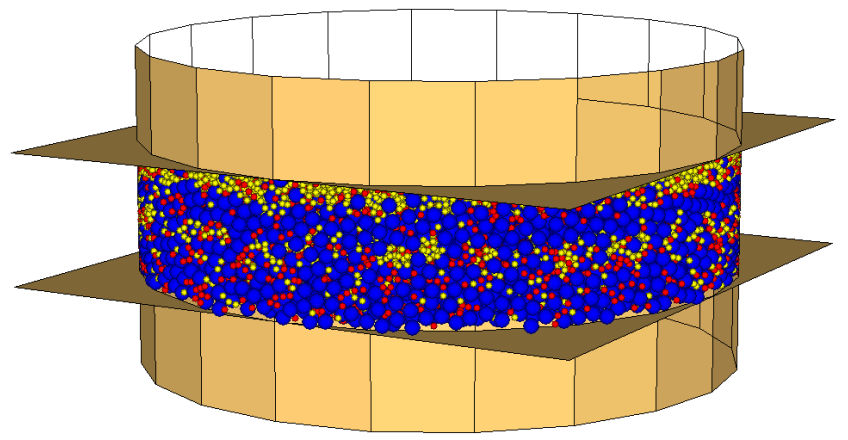

Figure 4. Mas1.2, DEM simulation (bitumen particles in blue, limestone filler particles in yellow, crumb rubber particles in red). 


\subsubsection{Description of the Contact Materials Parameters}

According to Vignali et al. [42], for each mastic the thermal properties and the contact model was defined.

As indicated by the manufacturer, thermal properties were selected for each component of the mastic (bitumen, limestone filler and crumb rubber) in terms of (Table 7):

- $\quad$ specific heat at constant volume;

- coefficient of linear thermal expansion; and

- thermal resistance per unit length.

Table 7. Thermal properties.

\begin{tabular}{cccc}
\hline Property & Bitumen & Limestone Filler & Crumb Rubber \\
\hline Specific heat at constant volume $\left(\mathrm{J} / \mathrm{kg} \cdot{ }^{\circ} \mathrm{C}\right)$ & 1630 & 908 & 1737 \\
Coefficient of linear thermal expansion $\left(1 /{ }^{\circ} \mathrm{C}\right)$ & $1.7 \times 10^{-5}$ & $8 \times 10^{-6}$ & $7 \times 10^{-5}$ \\
Thermal resistance per unit length $\left({ }^{\circ} \mathrm{C} / \mathrm{W} \cdot \mathrm{m}\right)$ & 5.88 & 0.80 & 5.20 \\
\hline
\end{tabular}

The contact model was defined choosing between two different approaches. In the existing literature, in fact, two different methods were used to build the DEM models with Burger's constitutive relations [47]:

- in the first one, linear contact model was applied, in which the normal and shear stiffness of a discrete element chang

- $\quad$ es with loading time, based on the Burger's constitutive relations [47,48]; and

- in the second, the embedded Burger's model was applied, in which the viscoelastic properties of a contact are defined with the Burger's constitutive relations and the model parameters are the stiffness or the viscosity at contact [49-52].

In this research study, the first approach was adopted.

It evaluates, in particular, the normal and shear stiffness of a discrete element by the following formulas [53,54]:

$$
\begin{aligned}
& k_{n}=\left[\frac{1}{K_{m n}}+\frac{t}{C_{m n}}+\frac{1}{K_{k n}} \cdot\left(1-e^{\frac{-t}{\tau_{n}}}\right)\right]^{-1} \\
& k_{n}=\left[\frac{1}{K_{m n}}+\frac{t}{C_{m n}}+\frac{1}{K_{k n}} \cdot\left(1-e^{\frac{-t}{\tau_{n}}}\right)\right]^{-1}
\end{aligned}
$$

where: $t$ is the loading time; $K_{m n}$ and $K_{m s}$ are the normal stiffness and the shear stiffness for Maxwell section, respectively; $C_{m n}$ and $C_{m s}$ are the normal viscosity and the shear viscosity for Maxwell section, respectively; $K_{k n}$ and $K_{k s}$ are the normal stiffness and the shear stiffness for Kelvin section, respectively; and $C_{k n}$ and $C_{k s}$ are the normal viscosity and the shear viscosity for Kelvin section, respectively. $\tau_{n}$ and $\tau_{s}$ are the normal and shear components of the relaxation time:

$$
\begin{gathered}
\tau_{n}=\frac{C_{k n}}{K_{k n}} \\
\tau_{s}=\frac{C_{k s}}{K_{k s}}
\end{gathered}
$$

It was decided to equate the normal and shear direction parameters:

$$
\begin{aligned}
& K_{m n}=K_{m s}=K_{m} \\
& C_{m n}=C_{m s}=C_{m}
\end{aligned}
$$




$$
\begin{aligned}
& K_{k n}=K_{k s}=K_{k} \\
& C_{k n}=C_{k s}=C_{k}
\end{aligned}
$$

The response of the Burger model to a constant shear stress is characterized using the dynamic shear compliance and the dynamic shear modulus. These relationships are presented in following equations:

$$
\begin{gathered}
\left|J^{*}(\omega)\right|=\sqrt{J^{\prime}(\omega)^{2}+J^{\prime \prime}(\omega)^{2}} \\
\left|G^{*}(\omega)\right|=\frac{1}{|J *(\omega)|}=\frac{1}{\sqrt{J^{\prime}(\omega)^{2}+J^{\prime \prime}(\omega)^{2}}} \\
J^{\prime}(\omega)=\left(\frac{1}{K_{m}}+\frac{K_{k}}{K^{2}{ }_{k}+\omega^{2} \cdot C^{2}{ }_{k}}\right) \\
J^{\prime \prime}(\omega)=\left(\frac{1}{\omega \cdot C_{m}}+\frac{\omega \cdot C_{k}}{K^{2}{ }_{k}+\omega^{2} \cdot C^{2}{ }_{k}}\right) \\
|G *(\omega)|=\frac{1}{\sqrt{\left(\frac{1}{K_{m}}+\frac{K_{k}}{K^{2}{ }_{k}+\omega^{2} \cdot C^{2}{ }_{k}}\right)^{2}+\left(\frac{1}{\omega \cdot C_{m}}+\frac{\omega \cdot C_{k}}{K^{2}{ }_{k}+\omega^{2} \cdot C^{2}{ }_{k}}\right)^{2}}}
\end{gathered}
$$

where: $G^{\prime}(\omega)$ is the real part referred to as the storage shear modulus; $G^{\prime \prime}(\omega)$ is the imaginary part referred to as the loss shear modulus; $J^{\prime}(\omega)$ is the real part referred to as the storage shear compliance; and $J^{\prime \prime}(\omega)$ is the imaginary part referred to as the loss shear compliance.

Burger's model parameters, in particular, were obtained by fitting to DSR measurements, according to the method developed by Baumgaertel and Winter [55]. The fitting procedure was based on minimizing an objective function corresponding to the sum of square of errors in predicting the storage and loss shear moduli over the available range of testing frequencies $[48,53]$ :

$$
\text { objective_function }=\sum_{j=1}^{m}\left[\left(\frac{G^{\prime}\left(\omega_{j}\right)}{G_{J}^{\prime 0}}-1\right)^{2}+\left(\frac{G^{\prime \prime}\left(\omega_{j}\right)}{G_{J}^{\prime \prime}}-1\right)^{2}\right]
$$

where: $G^{\prime}{ }_{j}^{0}$ and $G^{\prime \prime}{ }_{j}^{0}$ are, respectively, the storage and loss shear moduli measured at the $j$ th frequency $\omega_{j} ; G_{j}^{\prime}$ and $G^{\prime \prime}{ }_{j}$ are, respectively, the predicted storage and shear moduli; and $m$ is the number of data points. The "Solver" option in Microsoft Excel was utilized for minimizing the objective function (Table 8).

Table 8. Burger values.

\begin{tabular}{cccc}
\hline \multirow{2}{*}{ Contact Model Parameter } & \multicolumn{3}{c}{ “Solver" Value } \\
\cline { 2 - 4 } & MasSMA & Mas0.7 & Mas1.2 \\
\hline Stiffness for Kelvin section (MPa) & 0.13 & 0.10 & 0.19 \\
Stiffness for Maxwell section (MPa) & 22.67 & 5.51 & 13.90 \\
Viscosity for Kelvin section (MPa.s) & 6.97 & 2.10 & 7.72 \\
Viscosity for Maxwell section (MPa·s) & 44.50 & 37.46 & 144.59 \\
\hline
\end{tabular}

\subsubsection{Boundary and Loading Conditions of the Frequency Sweep Test}

According to Vignali et al. [42], an oscillatory shear load of constant amplitude was applied on the upper parallel wall, at several temperatures (between 10 and $60^{\circ} \mathrm{C}$ ) and different loading frequencies ranging between 0.01 and $10 \mathrm{~Hz}$. Since in PFC forces can be applied only to balls and not to walls, an oscillatory shear angular velocity was used for each temperature. This velocity depends directly on 
the frequency amplitude, corresponding to the deformation of the linear viscoelastic range obtained in the amplitude sweep test.

\subsubsection{Obtained Results}

The results of numerical and laboratory tests have been analyzed, evaluating both the macro-scale and the particle-scale response.

\section{Macro-Scale Results}

Numerical results have been evaluated in terms of complex modulus $\left(\left|G^{*}\right|\right)$ and phase angle $(\delta)$.

The first was calculated as a function of the maximum amplitude of the particles shear contact forces $\left(F_{S M A X}\right)$ and displacements $\left(S_{S M A X}\right)$, using Equation (25):

$$
|G *|=\frac{\left|F_{S_{M A X}}\right|}{\left|S_{S_{M A X}}\right|}
$$

The second was evaluated as a function of the time lag between the peak shear contact force and the peak shear displacement $(\Delta t)$ and of the loading time of one cycle $(t)$ using Equation (26):

$$
\delta=\frac{\Delta t}{t} \cdot 360
$$

Figures 5-7 compare the $G^{*}$ and $\delta$ master curves from the DEM simulation with the lab results, for each type of mastic. For all mastics, the measured data and the simulated ones have very similar trends, confirming that the DEM approach and assumptions used in this study, have good potential in predicting the mastic response in the frequency sweep configuration.

In all tests, the complex modulus decreases and the phase angle increases with increasing temperature (Figure 8). In particular, the differences between the mastics containing fine crumb rubber and limestone filler (Mas0.7 and Mas1.2) and the MasSMA, containing only limestone filler, are consistent.

At high temperatures, Mas0.7 and Mas1.2 show a better response to shear stresses, attaining $G^{*}$ values higher than MasSMA. This tendency increases with the increase of crumb rubber content.

At high frequencies, the crumb rubber properties reduce the mastic complex modulus and Mas1.2 appears less rigid than the MasSMA containing only limestone filler.

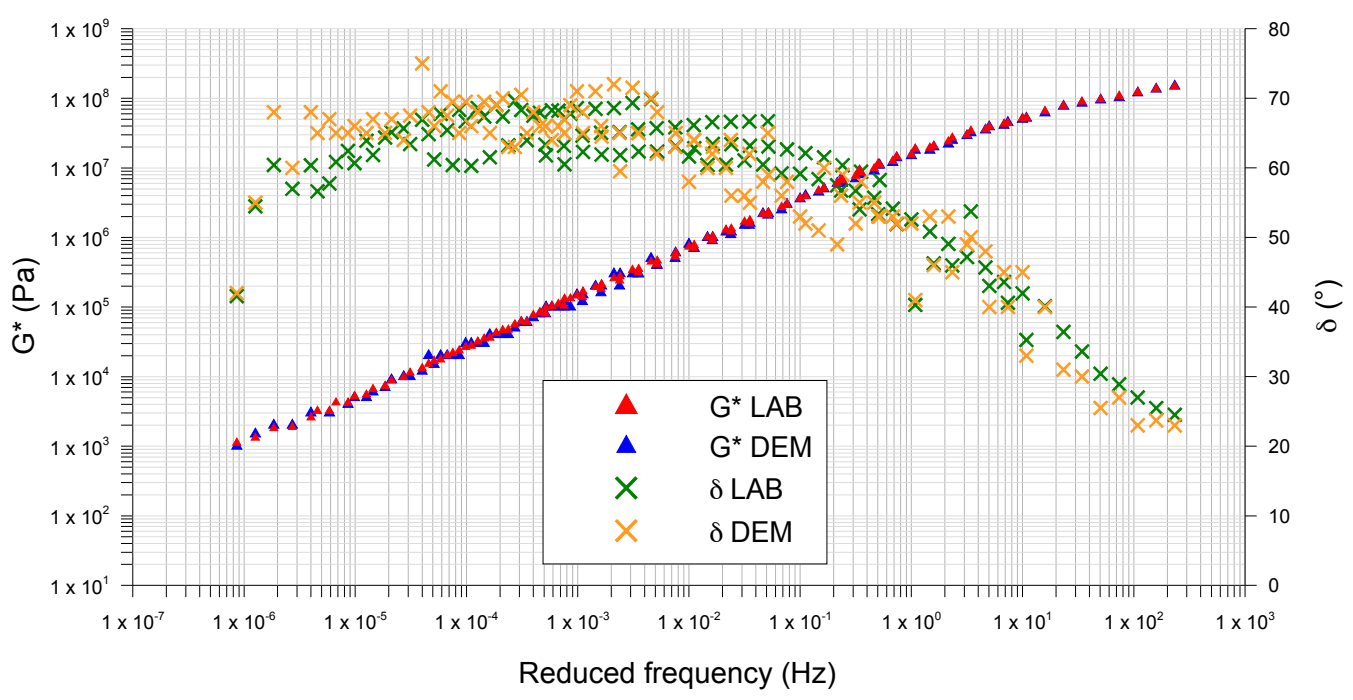

Figure 5. MasSMA, comparison between laboratory (LAB) and modeled (DEM) master curves. 
The master curves of phase angle also confirm this trend: at high temperatures, the elastic response of the mastic containing both rubber and limestone filler increases, exalting significantly the elastic behavior given by the polymer. At medium and low temperatures, the stress response of mastics Mas 0.7 and Mas1.2 shows phase angles lower than the ones of mastics containing limestone filler.

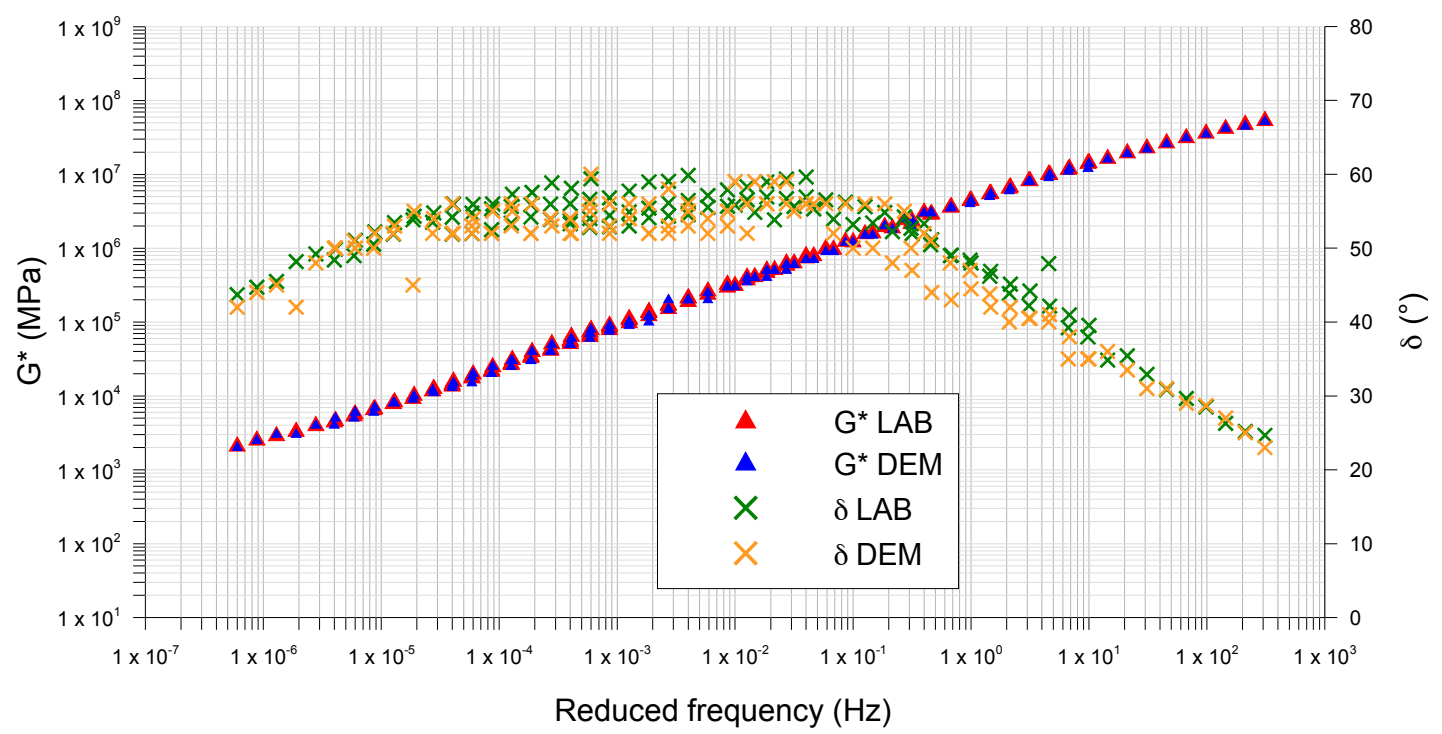

Figure 6. Mas0.7, comparison between laboratory (LAB) and modeled (DEM) master curves.

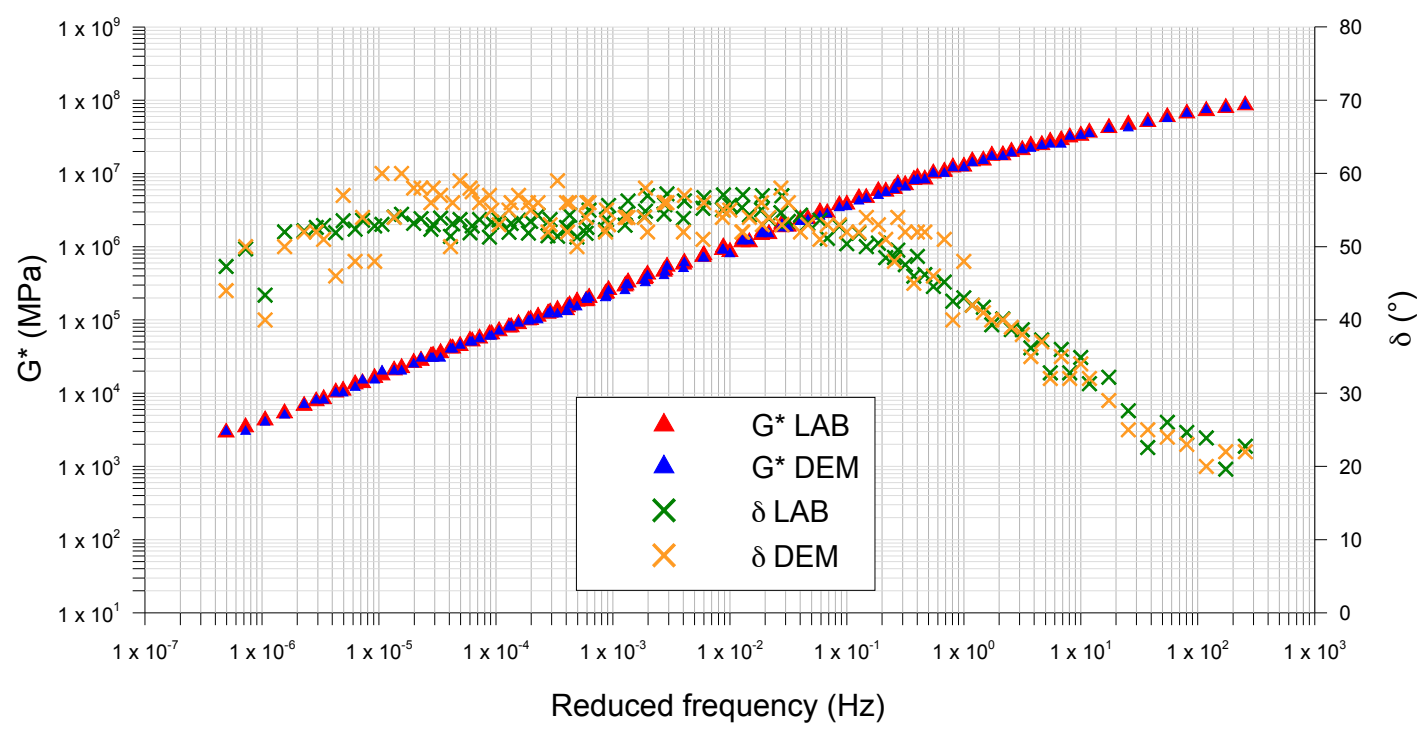

Figure 7. Mas1.2, comparison between laboratory (LAB) and modeled (DEM) master curves. 


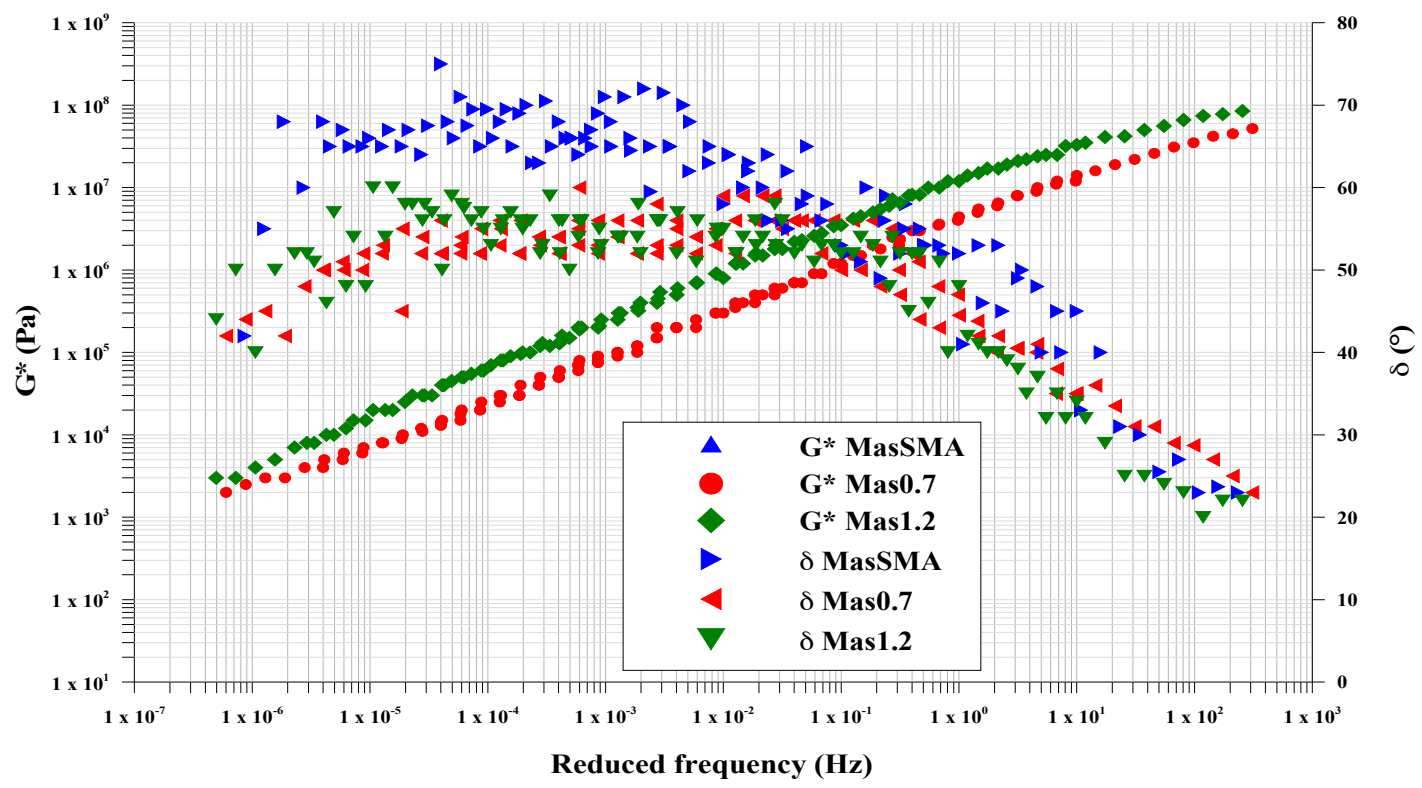

Figure 8. DEM master curves for all mastics.

Table 9 shows the mean error between DEM and lab data, for $G^{*}$ and $\delta$. The obtained values are very small, confirming that the DEM approach used is effective in predicting the mastics response in the frequency sweep configuration.

Table 9. Mean error between LAB and DEM data for all mastics (\%).

\begin{tabular}{ccc}
\hline Property & $G^{*}$ & $\delta$ \\
\hline MasSMA & 6.67 & 4.45 \\
Mas1.2 & 4.94 & 3.45 \\
Mas0.7 & 5.93 & 4.04 \\
\hline
\end{tabular}

The mean error is higher for the complex modulus than for the phase angle (Table 10). It always decreases with increasing of frequency, passing from low frequencies (LF) to medium ones (MF) and to high ones (HF). The complex modulus and phase angle, in all the range of frequency, the mean error decreases with the increasing of the crumb rubber content.

Table 10. Mean error between LAB and DEM data for all mastics at difference frequency ranges (\%).

\begin{tabular}{ccccccc}
\hline \multirow{2}{*}{ Property } & \multicolumn{3}{c}{$G^{*}$} & & & $\delta$ \\
\cline { 2 - 7 } & LF & MF & HF & LF & MF & HF \\
\hline Mas1.2 & 6.15 & 5.66 & 3.20 & 4.00 & 3.41 & 3.10 \\
Mas0.7 & 7.14 & 6.94 & 3.51 & 4.78 & 4.07 & 3.45 \\
MasSMA & 9.30 & 7.39 & 3.84 & 5.10 & 4.44 & 4.04 \\
\hline
\end{tabular}

\section{Micro-Scale Results}

The particle-scale response was analyzed by considering both the contact forces between spheres and their displacements inside the specimens.

In order to evaluate the influence of crumb rubber as a filler on the mastic behavior, contact forces and particle displacements have been evaluated inside the modeled samples at the end of the frequency sweep test, at three different temperatures $\left(10,30\right.$ and $\left.60^{\circ} \mathrm{C}\right)$. Ten degrees Celsius is representative of low temperatures and high frequencies, at which crumb rubber content gives to the 
mix a better response to shear stresses. Sixty degrees Celsius is representative of high temperatures and low frequencies, at which the limestone filler have larger effects on the mastic.

Due to the orientation of shear stresses, contact forces are mainly horizontally oriented. Shear contact forces have a uniform distribution inside the specimen and they are significantly larger than normal ones.

As the temperature increases, the maximum shear contact force inside the sample increases for each mastic (Table 11). The trend confirms the ability of crumb rubber, as a filler, to improve the sample complex modulus and the mastic resistance to permanent deformations at high temperatures.

Table 11. Maximum shear contact force inside the specimen $\left(10^{-3} \mathrm{~N} / \mathrm{m}\right)$.

\begin{tabular}{cccc}
\hline Temperature $\left({ }^{\circ} \mathbf{C}\right)$ & $\mathbf{1 0}$ & $\mathbf{3 0}$ & $\mathbf{6 0}$ \\
\hline MasSMA & 2.809 & 6.173 & 11.357 \\
Mas0.7 & 2.015 & 6.012 & 14.567 \\
Mas1.2 & 2.477 & 8.138 & 17.323 \\
\hline
\end{tabular}

The spheres' displacements have been evaluated in a Cartesian coordinate system with:

- origin in the center of the upper horizontal plane of the model, which simulates the oscillating plate;

- $\quad \mathrm{z}$ direction coincident to the vertical axis of symmetry of the sample, pointing to the lower plate.

For each mastic, from 10 to $60^{\circ} \mathrm{C}$, the total number of spheres displacements inside the sample increases and the 3D contacts network is characterized by a better interconnection between particles.

As shown in Table 12, for the same mastic, as the temperature increases, the maximum and minimum displacements of the particles in $x, y$ and $z$ directions increase. The $z$ displacement component is always smaller than the $\mathrm{x}$ and $\mathrm{y}$ ones.

Table 12. Maximum (sup) and minimum (inf) particles displacements in x (xdisp), y (ydisp) and z (zdisp) direction (mm).

\begin{tabular}{cccccccc}
\hline Temperature $\left({ }^{\circ} \mathbf{C}\right)$ & Mastic & xdisp inf & xdisp sup & ydisp inf & ydisp sup & zdisp inf & zdisp sup \\
\hline \multirow{3}{*}{10} & MasSMA & 0.000039 & 0.95 & 0.000038 & 1.10 & 0.000001 & 0.11 \\
& Mas0.7 & 0.000041 & 1.29 & 0.000042 & 1.22 & 0.000001 & 0.14 \\
& Mas1.2 & 0.000040 & 1.31 & 0.000040 & 1.29 & 0.000001 & 0.14 \\
\hline \multirow{3}{*}{30} & MasSMA & 0.000049 & 1.50 & 0.000045 & 1.40 & 0.000003 & 0.30 \\
& Mas0.7 & 0.000050 & 1.60 & 0.000048 & 1.70 & 0.000004 & 0.41 \\
& Mas1.2 & 0.000043 & 1.40 & 0.000044 & 1.35 & 0.000002 & 0.20 \\
\hline \multirow{3}{*}{60} & MasSMA & 0.000060 & 2.10 & 0.000056 & 2.20 & 0.000007 & 0.80 \\
& Mas0.7 & 0.000055 & 1.80 & 0.000052 & 2.01 & 0.000006 & 0.67 \\
& Mas1.2 & 0.000047 & 1.70 & 0.000045 & 1.80 & 0.000005 & 0.50 \\
\hline
\end{tabular}

At high temperatures (low frequencies), MasSMA shows larger spheres displacements than the Mas0.7 and Mas1.2 ones, while at low temperatures (high frequencies) Mas1.2 shows the maximum displacements. At $10{ }^{\circ} \mathrm{C}$, inside this sample with limestone and crumb rubber fillers, the particles move more independently of each other. Thus, the master curve trend, which shows that at high temperatures Mas1.2 is stiffer than MasSMA, is confirmed by the displacements of the spheres.

To better analyze the elastic behavior produced by crumb rubber, as a filler, on the mastic performance, the balls elastic displacements were evaluated.

These last were calculated on the horizontal plane of symmetry of the specimens (plane A-A), in order to discard the effect of the motion of parallel plates.

The elastic displacements have been evaluated on the A-A plane, for each temperature $(10,30$ and $60{ }^{\circ} \mathrm{C}$ ), as the difference $(\Delta)$ between the average displacement at the end of the test (loading frequency 
equal to $10 \mathrm{~Hz}$ ) and the average one at the beginning of the test (loading frequency equal to $0.01 \mathrm{~Hz}$ ). Hence, a small difference means that the average displacements at the beginning and at the end of the test are almost equal. Thus, it is an indicator of the material elasticity.

As shown in Table 13, at each temperature, $\Delta$ decreases from MasSMA, to Mas0.7 and to Mas1.2, confirming the elastic behavior produced by crumb rubber, as a filler, on the mastic performance.

Table 13. Average displacement on the horizontal plane of symmetry of the specimens at the end of the test (Disp A-A $10 \mathrm{~Hz}$ ) and at the beginning of the test (Disp A-A $0.01 \mathrm{~Hz})(\mathrm{mm})$.

\begin{tabular}{ccccc}
\hline Temperature $\left({ }^{\circ} \mathbf{C}\right)$ & Mastic & Disp A-A 0.01 Hz & Disp A-A 10 Hz & $\boldsymbol{\Delta}$ \\
\hline \multirow{2}{*}{10} & MasSMA & 0.295 & 0.580 & 0.285 \\
& Mas0.7 & 0.560 & 0.796 & 0.131 \\
& Mas1.2 & 0.665 & 0.595 & 0.035 \\
\hline \multirow{3}{*}{30} & MasSMA & 0.950 & 1.060 & 0.225 \\
& Mas0.7 & 0.835 & 1.195 & 0.115 \\
& Mas1.2 & 1.080 & 0.980 & 0.030 \\
\hline \multirow{2}{*}{60} & MasSMA & 1.160 & 1.475 & 0.470 \\
& Mas0.7 & 1.145 & 1.265 & 0.120 \\
& Mas1.2 & 1.005 & 1.180 & 0.020 \\
\hline
\end{tabular}

\section{Mastic Resistance Performance}

The evaluation of the permanent deformation resistance of the mastics was conducted also in the nonlinear analysis, through a performance approach that comprises Multiple Stress Creep Recovery (MSCR) tests.

According to ASTM D7405 [56], these have been operated in the rotational mode at $58^{\circ} \mathrm{C}$, using $1 \mathrm{~s}$ creep load followed by $9 \mathrm{~s}$ recovery for each cycle. Ten creep and recovery cycles were run at $0.1 \mathrm{kPa}$ creep stress, followed by ten at $3.2 \mathrm{kPa}$ creep stress. For each cycle, two parameters were calculated: the percent recovery $(\% \mathrm{R})$ and the non-recoverable creep compliance $\left(\mathrm{J}_{\mathrm{nr}}\right)$.

Figure 9 illustrates the results of the first cycle at $0.1 \mathrm{kPa}$, at the test temperature of $58{ }^{\circ} \mathrm{C}$. MasSMA accumulated the highest shear strain percentage. Mas1.2 and Mas0.7 show the same shear strain percentage. However the Mas1.2 reaches the minimum shear strain at the end of the $1 \mathrm{~s}$ shear stress application.

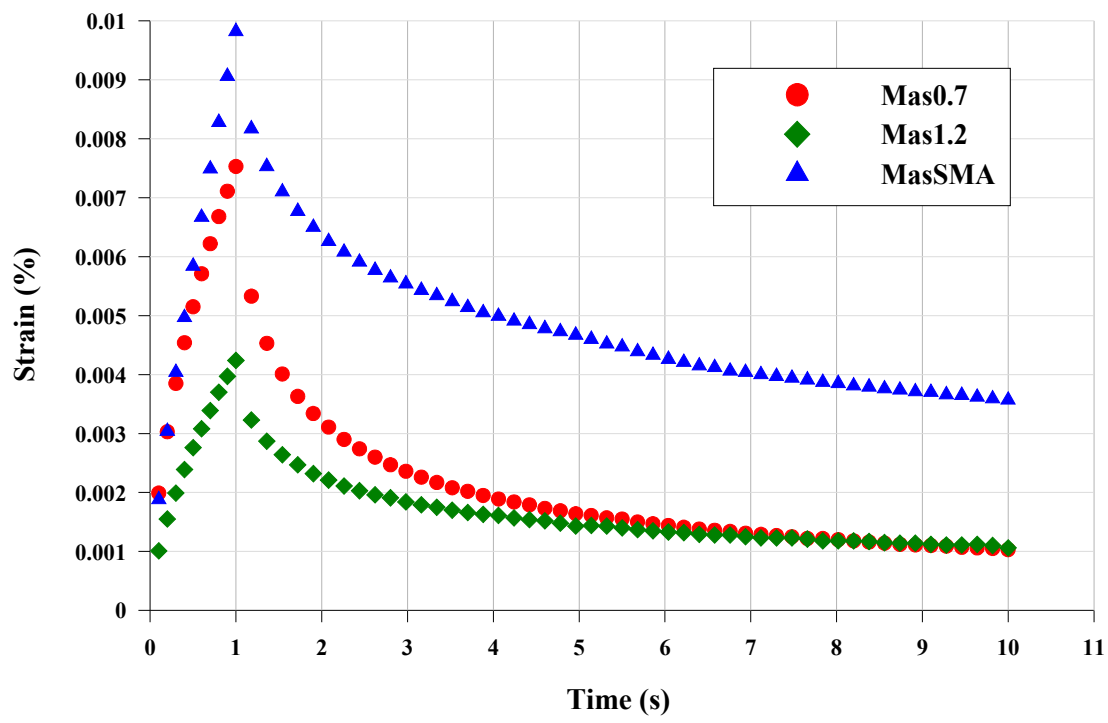

Figure 9. Shear strain vs. time, 1 st cycle, $0.1 \mathrm{kPa}, 58{ }^{\circ} \mathrm{C}$. 
Figure 10 illustrates the results of the first cycle at $3.2 \mathrm{kPa}$, at the test temperature of $58{ }^{\circ} \mathrm{C}$. In addition, in this case, MasSMA accumulated the highest shear strain percentage. However, increasing the shear stress level, for the mastic containing both limestone filler and fine crumb rubber, the shear strain percentage is not the same, like the previous case. Mas1.2, containing more rubber, accumulates a lower deformation than the Mas 0.7 .

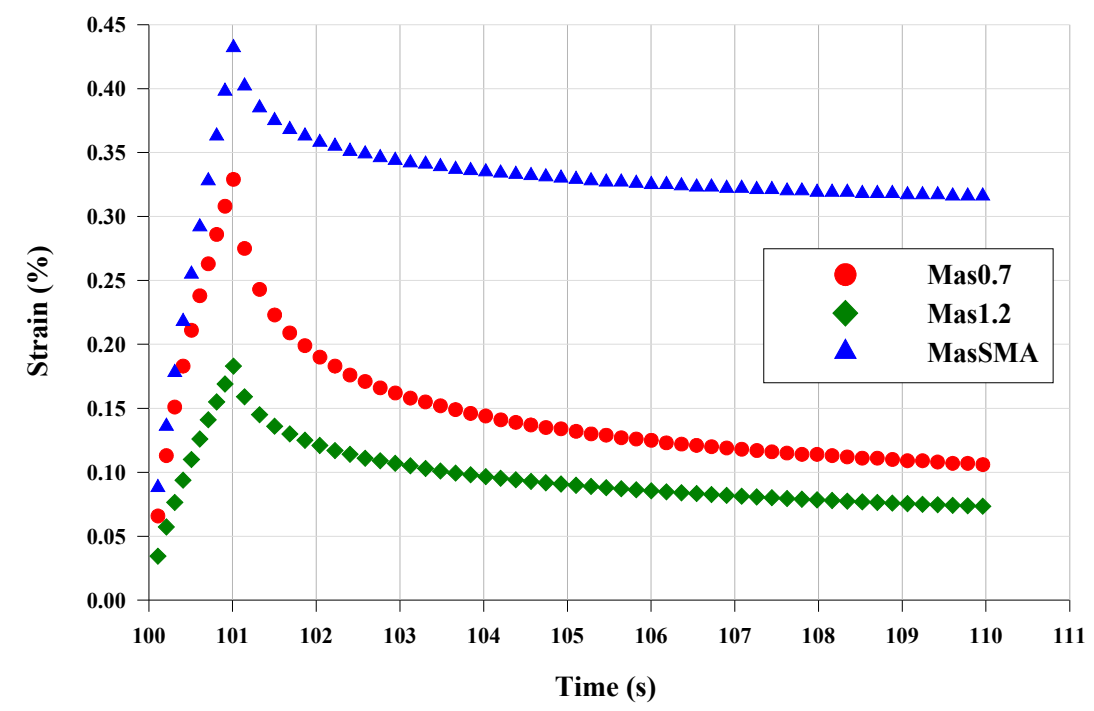

Figure 10. Shear strain vs. time, 1 st cycle, $3.2 \mathrm{kPa}, 58{ }^{\circ} \mathrm{C}$.

Figure 11 shows that the rate of strain value significantly increases when the $3.2 \mathrm{kPa}$ stress level starts. This effect goes up with crumb rubber reduction. Furthermore, the Mas1.2 always exhibits the stiffer behavior, accumulating less deformation at the end of the 10 cycles at $3.2 \mathrm{kPa}$, which the percentage of shear strain is roughly $0.5 \%$ at $58{ }^{\circ} \mathrm{C}$. Moreover, the largest shear strain percentage corresponds to MasSMA. The final shear strain percentage for MasSMA at $58{ }^{\circ} \mathrm{C}$ is approximately $2 \%$.

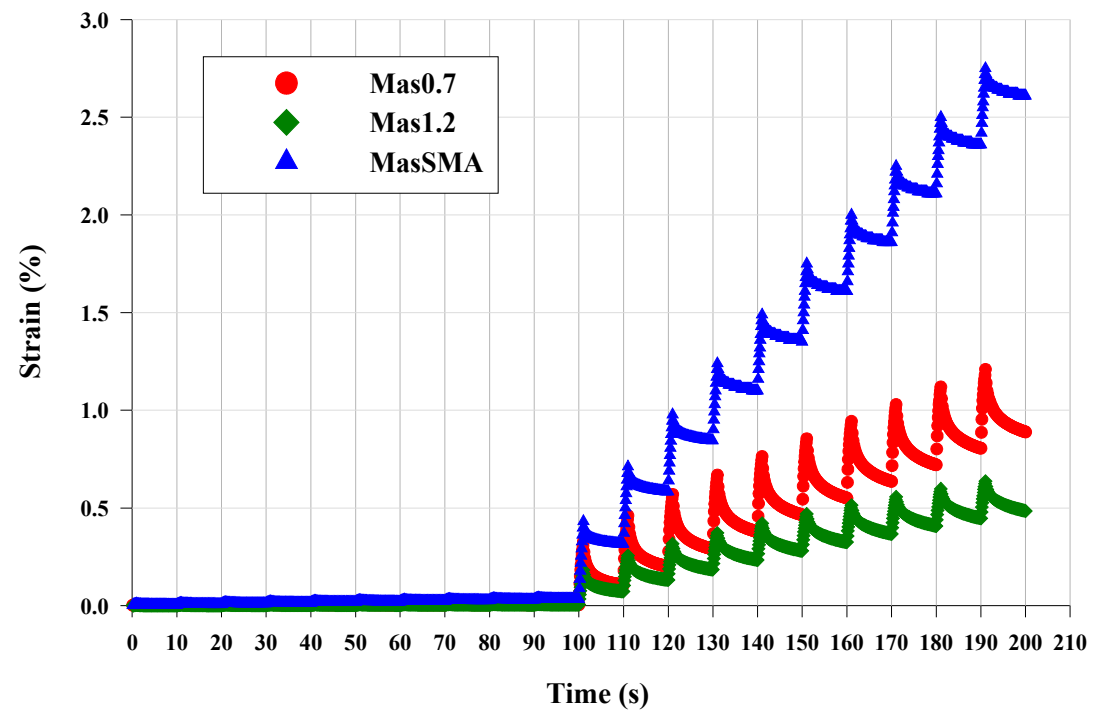

Figure 11. Shear strain vs. time, whole cycles, $58^{\circ} \mathrm{C}$.

The phase angle reduction shows in FS tests at high temperatures is visible in terms of percent recovery in MSCR tests (Table 14). MasSMA highlights the lowest percentage of recovery at both shear stress levels. Mas1.2 has the highest recovery percentages at 0.1 and $3.2 \mathrm{kPa}$. For Mas0.7 the percentage 
of recovery, at both shear stress level, is between the values of mastic containing only limestone filler and the one with the highest percentage of crumb rubber. As described on linear analysis, this result confirms that the limestone filler and crumb rubber action increases both stiffness and elastic mastic response at the high temperatures.

Table 14. Percentage of recovery of MSCR test at $0.1 \mathrm{kPa}$ and $3.2 \mathrm{kPa}$, at $58^{\circ} \mathrm{C}(1 / \mathrm{kPa})$.

\begin{tabular}{ccc}
\hline Mastic & $\mathbf{0 . 1} \mathbf{~ k P a}$ & $\mathbf{3 . 2} \mathbf{~ k P a}$ \\
\hline MasSMA & 40 & 20 \\
Mas1.2 & 87 & 32 \\
Mas0.7 & 61 & 25 \\
\hline
\end{tabular}

The creep compliance parameter $\left(\mathrm{J}_{\mathrm{nr}}\right)$ is a measure of the non-recoverable behavior of a binder caused by creep-recovery cycles. It is therefore suggested to describe the binder contribution to the asphalt mixture permanent deformations. In Table 15 are reported the $\mathrm{J}_{\mathrm{nr}}$ values under $0.1 \mathrm{kPa}$ and $3.2 \mathrm{kPa}$ shear stresses, at the test temperatures of $58^{\circ} \mathrm{C}$. Mas 1.2 has lower values of non-recoverable compliance at both shear stresses, showing a lower sensitivity to permanent deformations. In particular, at $3.2 \mathrm{kPa}$ Mas1.2 illustrates a $\mathrm{Jnn}_{\mathrm{nr}}$ value of $0.021 / \mathrm{kPa}$ at $58^{\circ} \mathrm{C}$, while the $\mathrm{J}_{\mathrm{nr}}$ values of MasSMA and Mas 0.7 are 0.08 and $0.031 / \mathrm{kPa}$ at the same shear stress and temperature. The $14 \%$ in weight of fine crumb rubber acts on the bitumen and makes the mastic more elastic and less susceptible to non-recoverable deformations. Mas1.2 is potentially less exposed to the phenomenon of permanent deformation. MSCR tests confirm the frequency sweep results. At high temperatures the $14 \%$ in weight of crumb rubber increases the shear stress response of the mastic.

Table 15. Creep compliance parameter (Jnr) of MSCR test at $0.1 \mathrm{kPa}$ and $3.2 \mathrm{kPa}$, at $58{ }^{\circ} \mathrm{C}(1 / \mathrm{kPa})$.

\begin{tabular}{ccc}
\hline Mastic & $\mathbf{0 . 1} \mathbf{~ k P a}$ & $\mathbf{3 . 2} \mathbf{~ k P a}$ \\
\hline MasSMA & 0.03 & 0.08 \\
Mas1.2 & 0.01 & 0.02 \\
Mas0.7 & 0.01 & 0.03 \\
\hline
\end{tabular}

\section{Conclusions}

Based upon the developed research work, the following concluding remarks can be made:

- The presence of fine crumb rubber and limestone filler improves the mastic stiffness at high temperatures, increasing the mastic rutting resistance. The frequency sweep tests and the Multiple Stress Creep Recovery have shown that at high temperatures the mastic containing crumb rubber and limestone filler has higher complex modulus than the one with only limestone filler.

- The fine crumb rubber reduces the mastic thermo-sensitivity, because at low temperatures the mastic containing both rubber and limestone filler not tends to glassy modulus, increasing the mastic resistance to thermal cracking.

- The Discrete particle Element Method is a valuable and hopeful tool to study the rheological behavior of asphalt mastics.

The obtained results show that the proposed "Dry-Hybrid Technology" confirms the feasibility of mixing fine rubber powder with a high workability modified bitumen and aggregates.

The obtained product is a modified bituminous mixture in which the rubber powder is mechanically added to the mixer, without significant alterations of the production process of a modified asphalt mixtures. The embedding to the mixer constitutes a continuity with the dry technique, which preserves the advantages in terms of absence of odors and of enhancement of the rheological properties of the binder. 
The rubber operates more as an active filler than as aggregate. It changes the rheological properties of the asphalt mix, increasing the stiffness at high temperatures and reducing the complex modulus at low temperatures.

The paraffinic wax in the bitumen, instead, can increase the workability of the modified binder inside of mixtures, whose volumetric proportioning of the components plays a key role the asphalt mixture elastic recovery increase.

The compatibility between powder and bituminous binder can be an advantage in the production of bitumen rich asphalts (SMA), for which the rubber can act as a stabilizer as the traditional fibers.

Acknowledgments: The authors gratefully acknowledge Ecopneus scpa and Dott. Daniele Fornai for the significant help given in carrying out the research study.

Author Contributions: Valeria Vignali performed the simulations and wrote the paper. Francesco Mazzotta performed the laboratory experiments and wrote the paper. Cesare Sangiorgi conceived and designed the experiments. Andrea Simone, Claudio Lantieri and Giulio Dondi analyzed the data.

Conflicts of Interest: The authors declare no conflict of interest.

\section{References}

1. Sangiorgi, C.; Tataranni, P.; Simone, A.; Vignali, V.; Lantieri, C.; Dondi, G. Waste bleaching clays as fillers in hot bituminous mixtures. Construct. Build. Mater. 2014, 73, 320-325. [CrossRef]

2. Mazzotta, F.; Sangiorgi, C.; Vignali, V.; Lantieri, C.; Dondi, G. Rheological characterization of bituminous mastics added with waste bleaching clays. In Proceedings of the 8th RILEM Symposium on Testing and Characterization of Sustainable and Innovative Bituminous Materials, Ancona, Italy, 7-9 October 2015.

3. Dondi, G.; Sangiorgi, C.; Lantieri, C.; Simone, A.; Vignali, V.; Lamperti, R. Performance evaluation of Construction and Demolition and other waste materials. In Proceedings of the 3rd International Conference on Transportation Infrastructures, ICTI 2014, Pisa, Italy, 22-25 April 2014.

4. Lamperti, R.; Grenfell, J.; Sangiorgi, C.; Lantieri, C.; Airey, G.D. Influence of waxes on adhesion properties of bituminous binders. Construct. Build. Mater. 2015, 76, 404-412. [CrossRef]

5. Sangiorgi, C.; Tataranni, P.; Simone, A.; Vignali, V.; Lantieri, C.; Dondi, G. Assessment of waste bleaching clay as alternative filler for the production of Porous Asphalts. Construct. Build. Mater. 2016, 109, 1-7. [CrossRef]

6. Lo Presti, D. Recycled Tyre Rubber Modified Bitumens for road asphalt mixtures: A literature review. Construct. Build. Mater. 2013, 49, 863-888. [CrossRef]

7. Fontes, L.P.T.L.; Trichês, G.; Pais, J.C.; Pereira, P.A.A. Evaluating permanent deformation in asphalt rubber mixtures. Construct. Build. Mater. 2009, 24, 1193-1200. [CrossRef]

8. Thodesen, C.; Xiao, F.; Amirkhanian, S.N. Modeling viscosity behavior of crumb rubber modified binders. Construct. Build. Mater. 2009, 23, 3053-3062. [CrossRef]

9. Dondi, G.; Mazzotta, F.; Simone, A.; Vignali, V.; Sangiorgi, C.; Lantieri, C. Evaluation of different short term aging procedures with neat, warm and modified binder. Construct. Build. Mater. 2016, 106, 282-289. [CrossRef]

10. Yildirim, Y.; Ideker, J.; Hazlett, D. Evaluation of viscosity values for mixing and compaction temperatures. J. Mater. Civ. Eng. 2006, 18, 545-553. [CrossRef]

11. Wei, J.; Huang, X.; Zhang, Y. Influence of commercial wax on performance of Asphalt. J. Mater. Civ. Eng. 2010, 22, 760-766. [CrossRef]

12. Oliveira, J.R.M.; Silva, H.M.R.D.; Abreu, L.P.F.; Fernandes, S.R.M. Use of a warm mix asphalt additive to reduce the production temperatures and to improve the performance of asphalt rubber mixtures. J. Clean. Prod. 2012, 41, 15-22. [CrossRef]

13. Lougheed, T.J.; Papagiannakis, A.T. Viscosity characteristics of rubber-modified asphalts. J. Mater. Civ. Eng. 1996, 8, 153-156. [CrossRef]

14. Xie, Z.; Shen, J. Performance of porous European mix (PEM) pavements added with crumb rubbers in dry process. Int. J. Pavement Eng. 2016, 17, 637-646. [CrossRef]

15. U.S. Department of Health and Human Services-Public Health Service-Centers for Disease Control and Prevention. Hazard Review-Health Effects of Occupational Exposure to Asphalt; Publication No. 2001-110; NIOSH—Publications Dissemination: Cincinnati, ON, USA, 2000. 
16. Fornai, D.; Persici, V.; Lupi, C. Occupational Health Risk Assessment for the Workers Exposed to Rubberized Asphalt Fumes. Available online: http://www.ecopneus.it/_public-file/Occupational\%20health\%20risk\% 20assessment $\% 20$ for $\% 20$ the $\% 20$ workers $\% 20$ exposed $\% 20$ to $\% 20$ rubberized $\% 20$ asphalt $\% 20$ fumes.pdf (accessed on 14 October 2016).

17. Woodward, D.; Millar, P.; Lantieri, C.; Sangiorgi, C.; Vignali, V. The wear of stone mastic asphalt due to slow speed high stress simulated laboratory trafficking. Construct. Build. Mater. 2016, 110, 270-277. [CrossRef]

18. Praticò, F.G.; Vaiana, R. A study on volumetric versus surface properties of wearing courses. Construct. Build. Mater. 2013, 38, 766-775. [CrossRef]

19. Vaiana, R.; Praticò, F.G.; Iuele, T.; Gallelli, V.; Minani, V. Effect of asphalt mix properties on surface texture: An experimental study. Appl. Mech. Mater. 2013, 368, 1056-1106. [CrossRef]

20. Boscaino, G.; Pratico', F.G.; Vaiana, R. Tyre/road noise on different road pavements: Synergetic influence of acoustical absorbing coefficient and surface texture. In Proceedings of the 10th EAEC European Congress, Belgrade, Serbia, 30 May-1 June 2005.

21. Abbas, A.; Masad, E.; Papagiannakis, T.; Shenoy, A. Modelling asphalt mastic stiffness using discrete element analysis and micromechanics-based models. Int. J. Pavement Eng. 2005, 6, 137-146. [CrossRef]

22. Zelelew, H.; Mahmoud, E.; Papagiannakis, T. Modeling asphalt concrete cyclic creep behavior. In Proceedings of the 3rd International Conference on Transportation Infrastructures, ICTI 2014, Pisa, Italy, 22-25 April 2014.

23. Buttlar, W.G.; Bozkurt, D.; Al-Khateeb, G.; Waldhoff, A.S. Understanding asphalt mastic behaviour through micromechanics. Transp. Res. Rec. 1999, 1681, 157-169. [CrossRef]

24. Dondi, G.; Simone, A.; Vignali, V.; Manganelli, G. Discrete particle element analysis of aggregate interaction in granular mixes for asphalt: Combined DEM and experimental study. In Proceedings of the 7th RILEM International Conference on Cracking in Pavements, Delft, The Netherlands, 20-22 June 2012.

25. Majidi, B.; Taghavi, S.M.; Fafard, M.; Ziegler, D.P.; Alamdari, H. Discrete element method modeling of the rheological properties of coke/pitch mixtures. Materials 2016, 9, 5. [CrossRef]

26. Particle Flow Code 3D; Itasca Consulting Group: Minneapolis, MN, USA, 2010.

27. Capitolato Speciale D'appalto—Norme Tecniche Pavimentazioni Stradali/Autostradali; ANAS spa; ANAS spa: Rome, Italy, 2012.

28. Bitumen and Bituminous Binders. Determination of Needle Penetration; EN 1426; British Standards Institution: London, UK, 2015.

29. Bitumen and Bituminous Binders. Determination of the Softening Point. Ring and Ball Method; EN1427; British Standards Institution: London, UK, 2015.

30. Bitumen and Bituminous Binders. Determination of the Tensile Properties of Modified Bitumen by the Force Ductility Method; EN13589; British Standards Institution: London, UK, 2008.

31. Bitumen and Bituminous Binders. Determination of Dynamic Viscosity by Vacuum Capillary; EN12596; British Standards Institution: London, UK, 2007.

32. Bitumen and Bituminous Binders. Determination of the Elastic Recovery of Modified Bitumen; EN13398; British Standards Institution: London, UK, 2007.

33. Tests for Geometrical Properties of Aggregates. Assessment of Fines. Grading of Filler Aggregates (Air Jet Sieving); EN 933-10; British Standards Institution: London, UK, 2009.

34. Tests for Mechanical and Physical Properties of Aggregates. Determination of the Particle Density of Filler. Pyknometer Method; EN 1097-7; British Standards Institution: London, UK, 2008.

35. Tests for Mechanical and Physical Properties of Aggregates. Determination of the Voids of Dry Compacted Filler; EN 1097-4; British Standards Institution: London, UK, 2008.

36. Prove Sugli Aggregati Complementari (Filler) Utilizzati Nelle Miscele Bituminose-Parte 1: Prova con Anello e Biglia; EN 13179-1; British Standards Institution: London, UK, 2013.

37. Bitumen and Bituminous Binders-Determination of Complex Shear Modulus and Phase Angle-Dynamic Shear Rheometer (Dsr); EN 14770; British Standards Institution: London, UK, 2012.

38. Dondi, G.; Mazzotta, F.; Sangiorgi, C.; Pettinari, M.; Simone, A.; Vignali, V.; Tataranni, P. Influence of cement and limestone filler on the rheological properties of mastic in cold bituminous recycled mixtures. In Proceedings of the 3rd International Conference on Transportation Infrastructures, ICTI 2014, Pisa, Italy, 22-25 April 2014.

39. Tan, Y.; Guo, M. Study on the phase behavior of asphalt mastic. Construct. Build. Mater. 2013, 47, 311-317. [CrossRef] 
40. Trinkle, S.; Friedrich, C. Van Gurp-Palmen-plot: A way to characterize polydispersity of linear polymers. Rheol. Acta 2001, 40, 322-328. [CrossRef]

41. Zheng, Q.; Du, M.; Yang, B.B.; Wu, G. Relationship between dynamic rheological behavior and phase separation of poly (methyl methacrylate)/poly (styrene-co-acrylonitrile). Polymer 2001, 42, 5743-5747. [CrossRef]

42. Vignali, V.; Mazzotta, F.; Sangiorgi, C.; Simone, A.; Lantieri, C.; Dondi, G. Rheological and 3D DEM characterization of potential rutting of cold bituminous mastics. Construct. Build. Mater. 2014, 73, 339-349. [CrossRef]

43. Wu, J.; Collop, A.C.; McDowell, G.R. Discrete element modeling of constant strain rate compression tests on idealized asphalt mixture. J. Mater. Civ. Eng. 2011, 23, 2-11. [CrossRef]

44. Collop, A.C.; McDowell, G.R.; Lee, Y. Use of the distinct element method to model the deformation behavior of an idealized asphalt mixture. Int. J. Pavement Eng. 2004, 5, 1-7. [CrossRef]

45. Kose, S.; Guler, M.; Bahia, H.H.; Masad, E. Distribution of strains within asphalt binders in HMA using imaging and finite element techniques. In Proceedings of the 79th Annual Meeting on Transportation Research Board, Washington, DC, USA, 9-13 January 2000.

46. Hammoum, F.; De la Roche, C.; Piau, J.M.; Stefani, C. Experimental investigation of fracture and healing of bitumen at pseudo-contact of two aggregates. In Proceedings of the 9th International Conference on Asphalt Pavements, Copenhagen, Denmark, 17-22 August 2002.

47. Collop, A.C.; McDowell, G.R.; Lee, Y. On the use of discrete element modelling to simulate the viscoelastic deformation behaviour of an idealized asphalt mixture. Geomech. Geoeng. 2007, 2, 77-86. [CrossRef]

48. Abbas, A.; Masad, E.; Papagiannakis, T.; Shenoy, A. Micromechanical modelling of the viscoelastic behavior of asphalt mixtures using the discrete-element method. Int. J. Geomech. 2007, 7, 131-139. [CrossRef]

49. Liu, Y.; You, Z. Simulation of cyclic loading tests for asphalt mixtures using user defined models within discrete element method. In Proceedings of the Geocongress, ASCE, Reston, VA, USA, 9-12 March 2008.

50. Liu, Y.; Dai, Q.; You, Z. Viscoelastic model for discrete element simulation of asphalt mixtures. J. Eng. Mech. 2009, 135, 324-333. [CrossRef]

51. Chen, J.; Pan, T.; Huang, X. Discrete element modeling of asphalt concrete cracking using a user-defined three-dimensional micromechanical approach. J. Wuhan Univ. Technol. Mater. 2011, 26, 1215-1221. [CrossRef]

52. Adhikari, S.; You, Z. 3D discrete element models of the hollow cylindrical asphalt concrete specimens subject to the internal pressure. Int. J. Pavement Eng. 2010, 11, 429-439. [CrossRef]

53. Zelelew, H.M. Simulation of the Permanent Deformation of Asphalt Concrete Mixtures Using Discrete Element Method (DEM). Ph.D. Thesis, Department of Civil and Environmental Engineering, Washington State University, Pullman, WA, USA, 2008.

54. Abbas, A. Simulation of the Micromechanical Behavior of Asphalt Mixtures Using the Discrete Element Method. Ph.D. Thesis, Washington State University, Pullman, WA, USA, 2008.

55. Baumgaertel, M.; Winter, H.H. Determination of discrete relaxation and retardation time spectra from dynamic mechanical data. Rheol. Acta 1989, 28, 511-559. [CrossRef]

56. Standard Test Method for Multiple Stress Creep and Recovery (MSCR) of Asphalt Binder Using a Dynamic Shear Rheometer; ASTM D7405; ASTM International: West Conshohocken, PA, USA, 2015.

(C) 2016 by the authors; licensee MDPI, Basel, Switzerland. This article is an open access article distributed under the terms and conditions of the Creative Commons Attribution (CC-BY) license (http://creativecommons.org/licenses/by/4.0/). 